\title{
FACTORS INFLUENCING INFORMATION SYSTEMS SUCCESS IN PAPUA NEW GUINEA ORGANISATIONS: A CASE ANALYSIS.
}

\author{
Mr. Limbie Kelegai \\ School of Information Systems \\ Faculty of Information Technology, Queensland University of Technology \\ 2 George Street, Brisbane, Queensland \\ Australia \\ Phone: +6173864 1956 \\ Fax: +61739641969 \\ Email: 1.kelegai@student.qut.edu.au \\ Mr. Michael Middleton \\ School of Information Systems \\ Faculty of Information Technology, Queensland University of Technology \\ 2 George Street, Brisbane, Queensland \\ Australia \\ Phone: +61738642870 \\ Fax: $\quad+61739641969$
}

Email: m.middleton@qut.edu.au

\begin{abstract}
Information Systems (IS) applications have proliferated in Least Developed Countries (LDCs) as organisations in these countries begin to realise the benefits of utilising these technologies to improve business process and enhance productivity. However much IS implementation in LDCs has been unsuccessful. Successful approaches should take account of technological factors, and also heed social context including economic, political, cultural and behavioural influences. As a component of a wider study to identify factors that influence IS success in developing countries, this paper examines factors that have affected IS implementation in two Papua New Guinea (PNG) organisations.
\end{abstract}

\section{INTRODUCTION}

We have been investigating the factors influencing Information Systems (IS) success in organisations in PNG, including Information Technology (IT) preparedness. As part of that process, we have conducted a number of case studies. Here we discuss organisational, individual, and external (or contingency) issues that influence IS success in two PNG organisations. Initial indications are that these are representative of the wider range of organisations being studied.

IS implementation and success in organisations has received much attention over the years as it has been utilised to enhance productivity and meet organisational goals, particularly in Developed Countries (DCs). Recently IS implementation has increased in LDCs as organisations in these countries realise the benefits of utilising IT as development tools (Harris \& Davison, 1999). Despite increased implementation, the level of IS success may be far lower in LDCs.

Many studies on IS implementation success have been undertaken, and a number of these are referenced in the following section on success factor identification. Few have concentrated on LDCs along the lines of Anakwe, Anandarajan \& Igbaria (1999). There is growing concern that implementation and utilisation of IS is being undertaken with insufficient consideration of economic, social and political difficulties. Identifying the determinants for IS success within these differing settings is important in LDCs. Therefore this study takes this into account in investigation of IS implementation.

Investigation is undertaken at individual and organisational levels. Factors external to the enterprises are also considered. For example, the availability of skilled IS and IT professionals in the country and its effect on organisational IS implementation and sustainability. 


\section{IS SUCCESS MEASUREMENT}

\section{Identification of success factors}

Various approaches have been taken over the last two decades to study and classify IS research. For example, Lyytinen (1987) classified the approaches as: (a) IS architecture, (b) information need, (c) socio-technical, (d) evaluation, and (e) success factors. The success factors approach attempts to model user and organisational features to predict IS implementation outcomes. It is argued that if practitioners are aware of the 'factors and address them during implementation, the system is more likely to succeed', (Larsen \& Meyers 1999, p.397). Furthermore, Grover, Jeong \& Segars (1996) suggest that research devoted to the measurement of IS effectiveness may be categorised into four distinctive research streams. These streams are: (a) criteria demonstration: theoretical development and justification of criteria, (b) measurement: evaluation and statistical development of effectiveness measures, (c) criteria relationship: linking effectiveness criteria, and (d) antecedent of IS effectiveness: theoretical and statistical determination of antecedents to IS success. The study on antecedents of IS effectiveness mainly focuses on determinants of IS effectiveness rather than the criteria themselves. Over the years much attention has been paid to success factor approaches (for example by Delone \& McLean 1992, Jain 1997, Myers, Kappelman, \& Prybutok 1998). These approaches have been criticised for a number of reasons, such as viewing implementation as a static phenomenon and ignoring factors that can have varying levels of importance at various levels of implementation, inconsistency in defining success factors, and being based on an underlying mechanistic view of IS. The study and measure of effectiveness is difficult because of the multidimensional constructs and being subject to varying perceptions of stakeholders and evaluators. Furthermore these factors may be differentiated between DCs and LDCs as a consequence of their social/organisational and cultural settings.

Delone \& Mclean (1992) suggest 3 levels of analysis: process, organisational and individual. Their investigation surveyed 180 articles and proposed that the existing measures be classified in to six dimensions: (a) system quality, (b) information quality, (c) information use, (d) user satisfaction, (e) individual impact and (f) organisational impact. However it seems that this study identified only system issues and not the human issues. Other approaches to categorisation have included that of Ein-Dor, Segev, \& Orgad, (1993) who in their review of international and cross-cultural studies classified contributing factors as cultural, environmental, structural and procedural; and OdedraStraub (1993) who identified various factors contributing to failures (and success) by reviewing a number of case studies and classifying the levels as national and organisational; and Markus \& Robey (1988), who use the levels: individual, organisational and society.

The study by Bailey \& Pearson (1986) has received much attention and been adapted by many academics and practitioners, because of the reliability, content, and construct validity. It identified 39 factors that influence user IS satisfaction and proposed an instrument to measure them. Miller \& Doyle (1987) were among those to apply the Bailey \& Pearson's work. They attempted to measure IS effectiveness by surveying managers (i.e. at an individual level) of 21 financial institutions in South Africa, by adapting 24 of these factors. Although Bailey \& Pearson provided a solid foundation for evaluating individual response, Grover, Jeong \& Segars (1996) argue that a greater scope of IS effectiveness is necessary.

\section{IS success studies}

Ang, Davis \& Finlay (2001) in a recent study investigated the impact of IT on TQM in public organisations in Malaysia by measuring the extent of IT use at a macro level. The objective of the study was to determine if public sector organisations with differing levels of IT usage have different factors that facilitate or inhibit IT use. They categorised success factors into organisational, technological and external dimensions. The results indicated that organisational and technological factors had a strong influence on IT utilisation. In a similar environment Jain (1997) conducted a case study on IS implementation in five South-East Asian countries and attempted to identify organisational factors that contribute to IS success in the context of LDCs. 
Hence it seems that IS research has been non-cumulative and fragmented lacking an overarching framework regarding the context in which effectiveness criteria are applied. This study groups the influencing factors into three levels: individual, organisational and external and attempts to investigate these factors in organisations in PNG.

\section{METHODOLOGY EMPLOYED IN STUDY}

\section{Design}

This research adopted the study design as suggested by Miles \& Huberman (1994), in which two data collection approaches are alternated, beginning with exploratory qualitative fieldwork, leading to the development of quantitative instruments such as questionnaires to deepen the qualitative data and strengthen theory. Stage 2 of the study, which involves a questionnaire survey is currently in progress. A purposive framework of sampling was applied for this study (Neuman 2000; Yin 1994).

\section{Sample}

Requests in the form of letters were mailed to 50 organisations. They were selected from prior contacts and listings in the PNG Telephone directory. Of the 50 requests, $40 \%$ (20) replied and agreed to participate. No prior studies have been conducted in this domain, and with limited IS literature, little is known about IS implementation and success in organisations in PNG. Ten organisations were selected following the purposive framework as suggested and similar considerations to Jain (1997). Factors such as limitation of funding, location and difficulty accessing the sites, maturity of the IS and IT infrastructure in the organisations, law and order problems, and organisation size were considered during the process of selecting the cases.

\section{Method}

Case study reliability was sought using several strategies including case study protocol (Yin 1994, Jain 1997). It was reviewed and verified for face and content validity before being implemented. The protocol was further reviewed after the pilot study. A brief form of the procedures and protocol were mailed to the participating organisations together with the letter of introduction before the resumption of the study.

Interviews were conducted on site. The participants were grouped into 3 categorises, managers (top and middle), users, and IS staff. All interviews were transcribed verbatim and database created for all data collected during the field study. Using NVivo, a qualitative analysis package, qualitative data was coded and recoded into elementary parts, and than regrouped into categories such as those appearing in Table 2, 3, and 4.

Cultural interpretations used in interviews are described under 'cultural features' in the context section following.

\section{CONTEXT}

\section{PNG geography}

PNG has a population density of 8 persons per square kilometre, and annual population growth rate is estimated at $2.4 \%$. PNG has more languages (over 800 ) than any other country in the world, with the possible exception of India. The official language is English with Pidgin and Hiri Motu being used widely as lingua franca to facilitate communication among people of diverse linguistic backgrounds. Its parliamentary democracy elects a single legislature, the National Parliament. PNG has distinctive cultural norms. Like other LDCs, PNG's unstable political environment is one of the major hindrances to economic growth. Of its 4.5 million people, $85 \%$ live in rural areas.

For organisations to function effectively, an understanding, scanning and analysis of the environmental forces surrounding the firm is essential (Kavanamur 1996). Literature suggests that 
the environment in LDCs is volatile, and particularly with IT constantly changing. Table 1 presents a summary of the PNG environment.

\section{IT industry in PNG}

There appears to be no publicly documented evidence of the early implementation of IS or IT in PNG organisations. However organisations in the country were beginning to realise the benefits of using IT as a tool and increasingly employing IS at various levels. The IT industry is small but slowly developing, therefore relies on technology imported from foreign countries such as Australia. Given the opportunity PNGeans are able to adopt these technologies. The IT industry is driven by the industry itself, because as is argued by some respondents, there was a lack of IS or IT planning and direction at the national level. Other limitations include the lack of a national information infrastructure.

\section{Cultural features}

This study pays particular attention to the cultural factors that may have an influence on IS success. We have adapted Hofstede's (1983, p.23) approach with its definition of national culture as a 'collective programming of the mind which distinguishes the members of one group from those of another'. In this context, culture deals with a collective way of thinking by a group of people. Hall (1977) classified culture in two contexts, high context and low context. High context societies are characterised as collectivist, while low context societies are individualist. However a nation or country may not be classified has having a single culture (Hofstede, 1997; Myers \& Tan, 2002), thus acknowledging the presence of subcultures and individual differences within nations and regions. For example, in PNG there are more the 800 languages and different regions with varying cultural beliefs and values. Hofstede and Hall used classifications as follows:

- Individualism/Collectivism: Individualist societies have loosely knit social structure where individualist approaches are encouraged. Collectivist societies prefer tightly knit social framework where in-group ideals take precedent.

- Large/Small Power Distance(PD): This measures the extent to which the members of a society accept that power is distributed unequally. LPD has a hierarchical order in which everyone has a place with no justification. SPD societies strive for power equalisation.

- Strong/Weak Uncertainty Avoidance(UA): This measures the degree to which members of societies feel uncomfortable with uncertainty and ambiguity. Strong UA societies are less tolerant to deviant ideas and maintain rigid codes. Weak UA societies are more tolerant to deviance and are open to new ideas.

- Masculinity/Femininity: Masculine society prefers achievements, heroism assertiveness, and materialism and is less caring with an individualist approach. Femininity emphasises relationship, modesty and quality of life.

Each society arrives at its answers as a consequence of these fundamental issues, which represent the common element of structure in the cultural system of the country. PNG scores closer to a collectivist culture with an egalitarian social structure. 


\begin{tabular}{|c|c|c|}
\hline & PNG & Developed Countries \\
\hline \multicolumn{3}{|l|}{ A. Economic factors } \\
\hline Labour(IS Professionals) & scarce & abundant \\
\hline Agricultural/Industrial & agricultural & industrial \\
\hline \multicolumn{3}{|l|}{ Capital } \\
\hline GNP & $<\mathrm{US} \$ 744$ & $>\mathrm{US} \$ 15,000$ \\
\hline Inflation & high & low \\
\hline \multicolumn{3}{|l|}{ Infrastructure } \\
\hline National Information & weak & strong \\
\hline \multicolumn{3}{|l|}{ Infrastructure } \\
\hline \multicolumn{3}{|l|}{ Technology } \\
\hline Flow & recipient & donor \\
\hline Availability & scarce & abundant \\
\hline \multicolumn{3}{|l|}{ B. Political Factors } \\
\hline Instability & high & low \\
\hline Institutions & weak & strong \\
\hline \multicolumn{3}{|l|}{ C. Cultural Factors } \\
\hline Social structure & egalitarian & less rigid \\
\hline Uncertainty Avoidance & high & low \\
\hline Individual/Collective & collectivism & individualist \\
\hline Power Distance & high & low \\
\hline Masculinity-Femininity & femininity & masculinity \\
\hline Abstractive-associative thinking & $\begin{array}{l}\text { low abstractive; high } \\
\text { associative }\end{array}$ & $\begin{array}{l}\text { high abstractive; low } \\
\text { associative }\end{array}$ \\
\hline \multicolumn{3}{|l|}{ D. Work culture } \\
\hline Creative potential & limited & unlimited \\
\hline Time perspective & past and presented & future-oriented \\
\hline Time units of action & short term & long term \\
\hline Success orientation & moralism & pragmatism \\
\hline Environment & context dependent & context independent \\
\hline People orientation & paternalistic & participative \\
\hline
\end{tabular}

Table 1. Summary of environment factors in PNG (derived from interpretation by Kavanamur (2002) of factors identified by Hofstede (1997)

\section{CASE STUDIES}

\section{Brief description of the organisations} Organisation A

Organisation A is a semi government organisation established by an act of parliament as a Commercial Statutory Authority (CSA) .The organisation is autonomous, and operates on a commercial basis as stipulated under the Act.

\section{Organisation B}

Organisation B is a private organisation involved in the vehicle and spare parts industry. It is a division of a Group of Companies involved in a wide range of business activities throughout PNG with offices internationally.

\section{ICT in the organisations}

Organisation A has had wide experience in IS development, and implementation. There is also a high level of IT knowledge and literacy, particularly at the upper management level. In addition, top 
management is supportive of IS as a strategic tool to realise the organisation's objectives and achieve operational goals. Organisation A recently implemented a management information system. The system integrates finance, administrative and billing system. At the end user computing level, a range of desktop packages is utilised. These packages range from office automation systems such as MS Office Professional to engineering packages such as AUTOCAD.

Prior to the current management system, Organisation A implemented a system administered by a IS service organisation. The system was primarily used for invoicing and collection of rates in the operational centres. Their mainframe was located in Port Moresby and operational centres connected via dedicated lines with dumb terminals on each site. Organisation A migrated to a PC based environment with the assistance of expatriate consultant. A PNG national officer was recruited to understudy the consultant. The current system was developed overseas but customised to Organisation A's requirements. Data from remote sites were transferred electronically via email and processed in Port Moresby. Printed invoices were than posted to the respective districts.

Organisation B implemented two major computer information systems, a stock control system and the vehicle system supported, which were maintained by an organisation based outside the country. Organisation B is a division of a private organisation, therefore IS investments were assessed in terms of achieving efficiency in the organisation process with the primary objective to maximise its profit margin.

Table 2, 3, and 4 presents a comparison of IS success factors as interpreted in the organisations. They are accompanied by brief summaries of some of the identified factors

\begin{tabular}{|l|c|c|c|c|}
\hline \multicolumn{1}{|c|}{$\begin{array}{l}\text { Identified } \\
\text { Individual Factors }\end{array}$} & $\begin{array}{c}\text { Is the factor important for IS } \\
\text { success in the organisation? }\end{array}$ & $\begin{array}{c}\text { Is the factor achieved in the } \\
\text { organisation? }\end{array}$ \\
\cline { 2 - 5 } & $\begin{array}{c}\text { ORGANISAT } \\
\text { ION A }\end{array}$ & $\begin{array}{c}\text { Organisation } \\
\text { B }\end{array}$ & $\begin{array}{c}\text { Organisation } \\
\text { A }\end{array}$ & $\begin{array}{c}\text { Organisation } \\
\text { B }\end{array}$ \\
\cline { 2 - 5 } & $\begin{array}{c}\text { Mgr } \\
(3)\end{array}$ & $\begin{array}{c}\text { Mgr } \\
(3)\end{array}$ & $\begin{array}{c}\text { Mgr } \\
(3)\end{array}$ & $\begin{array}{c}\text { Mgr } \\
(3)\end{array}$ \\
\hline $\begin{array}{l}\text { Management IS } \\
\text { knowledge }\end{array}$ & yes & yes & yes & no \\
\hline Management Support & yes & yes & yes & mix \\
\hline Funding & yes & yes & no & mix \\
\hline $\begin{array}{l}\text { IS Division Service \& } \\
\text { Support }\end{array}$ & yes & yes & mix & yes \\
\hline $\begin{array}{l}\text { IS staff skill and } \\
\text { competency }\end{array}$ & yes & yes & mix & mix \\
\hline User training & yes & yes & no & yes \\
\hline Information availability & yes & yes & mix & yes \\
\hline Timeliness of report & yes & yes & mix & yes \\
\hline System availability & yes & yes & yes & yes \\
\hline System flexibility & yes & yes & yes & yes \\
\hline System Integrity & yes & yes & yes & yes \\
\hline
\end{tabular}

Table 2: Comparison of IS success factors, individual level 
Management IS knowledge and support.

The level of knowledge and literacy, and management understanding of IS contributes to the management's perception of IS, its responsibilities, usefulness and strategic value to the organisation. It may influence management's willingness to support IS. Top management in Organisation A perceive IS as a useful and strategic tool, and an integral part of the organisation. Respondents in Organisation B felt that, although top management perceived IS to be useful, they were apprehensive in pushing IS in the organisation, and required convincing before any actions were taken. One of the managers at Organisation B stated that they lacked 'support and push from the top'. The lack of IS knowledge and awareness may be a contributing factor to the lack of enthusiasm by top management. Therefore IS knowledge, literacy and understanding were important ingredients for top management to be better informed in order for them to support and source funds.

\begin{tabular}{|c|c|c|c|c|c|c|c|c|}
\hline \multirow{3}{*}{$\begin{array}{c}\text { Identified } \\
\text { Organisational } \\
\text { Factors }\end{array}$} & \multicolumn{4}{|c|}{$\begin{array}{l}\text { Is the factor important for IS success in } \\
\text { the organisation? }\end{array}$} & \multicolumn{4}{|c|}{$\begin{array}{l}\text { Is the factor implemented in the } \\
\text { organisation? }\end{array}$} \\
\hline & \multicolumn{2}{|c|}{$\begin{array}{l}\text { ORGANISATIO } \\
\text { N A }\end{array}$} & \multicolumn{2}{|c|}{ Organisation B } & \multicolumn{2}{|c|}{ Organisation A } & \multicolumn{2}{|c|}{ Organisation B } \\
\hline & $\begin{array}{c}\mathrm{Mg} \\
\mathrm{r} \\
(3)\end{array}$ & $\begin{array}{c}\text { CEO } \\
(1)\end{array}$ & $\begin{array}{l}\text { Mgr } \\
(3)\end{array}$ & CEO & $\begin{array}{l}\text { Mgr } \\
(3)\end{array}$ & $\begin{array}{l}\text { CEO } \\
(1)\end{array}$ & $\begin{array}{l}\text { Mgr } \\
(3)\end{array}$ & CEO \\
\hline $\begin{array}{l}\text { Management IS } \\
\text { knowledge }\end{array}$ & yes & yes & yes & & yes & yes & no & \\
\hline Management Support & yes & yes & yes & & yes & yes & mix & \\
\hline Funding & yes & yes & yes & & no & no & mix & \\
\hline Prioritising IS & yes & yes & yes & & yes & yes & yes & \\
\hline Strategic Tool & yes & yes & yes & & $\operatorname{mix}$ & yes & yes & \\
\hline $\begin{array}{l}\text { IS policy - } \\
\text { organisational }\end{array}$ & yes & yes & yes & & no & no & no & \\
\hline IS Planning & yes & yes & yes & & no & $\operatorname{mix}$ & no & \\
\hline CEO/CIO proximity & no & no & no & & no & no & no & \\
\hline
\end{tabular}

TABLE 3: COMPARISON OF IS SUCCESS FACTORS, ORGANISATIONAL LEVEL

\section{Funding}

Funding is considered an important IS success factor. In Organisation B, funding was available if management were in agreement that the IS project would yield more benefits for the organisation. With the increase in IS experience and newer technology, management were willing to invest in IS provided it increased benefits. Organisation A was able to internally fund some projects, unlike the other government organisations that totally rely on government funding. In addition, Organisation A was a recipient of donor assisted funding for its major projects including IS investment. However, there were concerns about the long-term sustainability and continuity of the donor funded projects. Furthermore, projects funded by international donor agencies may be helpful for good governance, however these projects should be developed within a framework and systematic policy commitment by the government. 


\section{Prioritising IS}

Organisations A and B regarded IS as a core business activity and a critical success factor. For instance, top management in Organisation A said that IS was 'critical and a top priority'. Therefore there is a high degree of IS support from the top management at organisation A. Similarly IS was considered a priority for Organisation B.

\section{IS policy \& planning}

Strategic issues such as IS policy and planning are significant guidelines for the organisations' IS development. However there was no IS policy and long term planning evident for either organisations. One manager in Organisation B stated that IS was 'mainly driven by need to automate because I do not think we have an IS policy, and, if there is a need and new things in the market we try to get them'. Similarly, it was stated that there was 'no IT policy' in place in Organisation A. It was also argued that long term IS planning was lacking in the organisations. For example, when the management system in Organisation A was upgraded to a new platform there were concerns and disagreement regarding the manner in which the new system was 'developed and implemented'. There had been no plans for the migration, therefore the migration process disrupted the organisations functions.

\section{IS division service and support}

The inability to provide effective IS service and support by IS division in the organisation may inhibit IS success. Managers in Organisation B were content with the services provided by the IS division, particularly with the network support and training. The organisation implemented off-theself packages purchased from service providers in the country and from vendors abroad, therefore there was no software development in Organisation B. There were only 3 IT support staff in Organisation B. The information system in Organisation A was specifically designed, developed and implemented by consultants. IS staff were primarily involved with administration and ongoing maintenance of the system. Respondents in Organisation A indicated that support and service from the IS division was inadequate. Only 2 IS staff were employed in Organisation A. 


\begin{tabular}{|c|c|c|c|c|c|c|}
\hline \multirow[t]{3}{*}{$\begin{array}{c}\text { Identified External } \\
\text { Factors }\end{array}$} & \multicolumn{4}{|c|}{$\begin{array}{l}\text { Is the factor important for IS success in } \\
\text { the organisation? }\end{array}$} & \multicolumn{2}{|c|}{ Is factor implications } \\
\hline & \multicolumn{2}{|c|}{$\begin{array}{c}\text { ORGANISATIO } \\
\text { N A }\end{array}$} & \multicolumn{2}{|c|}{ Organisation B } & \multirow[t]{2}{*}{ Organisation A } & \multirow[t]{2}{*}{ Organisation $B$} \\
\hline & $\begin{array}{c}\text { Mgr } \\
\text { (3) }\end{array}$ & $\begin{array}{l}\text { CEO } \\
(1)\end{array}$ & $\begin{array}{c}\mathrm{Mg} \\
\mathrm{r} \\
(3)\end{array}$ & CEO & & \\
\hline National IS policy & yes & yes & yes & & No clear policy & No clear policy \\
\hline $\begin{array}{l}\text { Availability of IS } \\
\text { professionals }\end{array}$ & yes & yes & yes & & Major concern & Major Concern \\
\hline Consultants & yes & yes & yes & & $\begin{array}{l}\text { Difficulty with } \\
\text { consultants }\end{array}$ & $\begin{array}{l}\text { Difficulty with } \\
\text { consultants }\end{array}$ \\
\hline $\begin{array}{l}\text { Government planning } \\
\text { and direction }\end{array}$ & yes & yes & yes & & $\begin{array}{l}\text { Lack planning and } \\
\text { direction }\end{array}$ & $\begin{array}{l}\text { Lack of planning } \\
\text { and direction }\end{array}$ \\
\hline $\begin{array}{l}\text { Telecommunication } \\
\text { Infrastructure }\end{array}$ & yes & yes & yes & & $\begin{array}{l}\text { Inadequate } \\
\text { infrastructure }\end{array}$ & $\begin{array}{l}\text { Inadequate } \\
\text { Infrastructure }\end{array}$ \\
\hline $\begin{array}{l}\text { National Cultural } \\
\text { Issues }\end{array}$ & yes & yes & yes & & Concern & Concern \\
\hline $\begin{array}{l}\text { Political \& Economic } \\
\text { conditions }\end{array}$ & yes & yes & yes & & Non conducive & Non conducive \\
\hline Law \& Order & yes & yes & yes & & Concern & Concern \\
\hline IS industry support & yes & yes & yes & & Lacking & Lacking \\
\hline
\end{tabular}

Table 4: Comparison of IS success factors, external level

\section{Availability of IS professionals}

Both organisations were in agreement that skilled IS professionals were scarce in PNG. One senior manager in Organisation B said that it was 'difficult to locate people with skills of specialised software packages'. Similarly in Organisation A it was stated that the country did not 'necessarily have the expertise', therefore it was difficult employing IS professionals from within the country. The availability of skilled IS staff is critical to the successful application of IS in organisations in the country.

\section{Foreign IS Consultants}

As a result of the lack of skilled IS professionals in the country, organisations 'engaged people from outside to assist in the IS development'. It was argued that generally, IS staff lack the knowledge, experience and confidence to engage in the development of large systems. Foreign IS consultants will continue to play a significant role in IS development and implementation in the two organisations. Thus organisations may have developed a culture of dependency on external consultants for the development and implementation of their information systems. A number of issues are highlighted:

- IS development projects were often incomplete. Because of the limitations in funding, consultants are engaged for a short period and may not complete the project within the scheduled period.

- Access and support: consultation with consultants who operated from overseas was through the phone or email, however 'communication through email was difficult'. 
There was no face-to-face contact. From a cultural perspective, generally collectivist societies prefer face-to-face contacts and tend to dislike other forms of communication.

- Training and knowledge transfer: it was argued that consultants failed to train IS staff and users. Consultants were engaged to 'fix' the immediate IS problem but did not place any emphasis on training and knowledge transfer.

- Reliance and high cost for consultants: consultant fees were a major cost area for both organisations. It was 'very expensive to bring people up to fix' the problems. However, with the lack of skilled IS professionals in the country, organisations have no choice but to rely on external consultants for assistance and direction.

\section{IS training}

Another identified IS success factor was training. Generally, the demand for IS training was identified at a number of levels; IS staff training, user training in the operations for a particular system, and a general IT literacy program on the evolving technologies.

IS training was essential for both organisations. In Organisation B, funds were committed for user training highlighting the organisations emphasis on IS training. Furthermore, IS experience in the organisation was relatively new, therefore IS knowledge and literacy programs may be required at all levels on a continuous basis.

Similarly, Organisation A 'emphasised IS training'. However managers felt that 'training was not very good'. Therefore IS literacy programs were essential. In general one respondent stated that 'we have the technology here but we have a problem of literacy and skills', and implied that there was a lack of training plan for IS staff and the users.

Finally, various types of training are required at all levels in both organisations 'for managers, users and IS staff'.

\section{Information satisfaction}

Both organisations emphasised information integrity and availability with a focus on information delivery. The quality and integrity of information delivered depends on a number of things including system integrity, and the quality of data input. The need for data input quality was emphasised by a senior manager in Organisation A that 'the important thing is the input'. Furthermore, system integrity was essential to manipulate and deliver the necessary information for business operations and decision-making, and importantly reliable information is presented to the customers on time. Managers require accurate information delivered on a timely basis

\section{Government stability and planning}

Environmental conditions in which organisations operate have an impact on their functions. In PNG, governments can change every 18 months as allowed by the constitution, thus projecting an atmosphere of political uncertainty. Uncertainty increases costs, interferes with planning and often leads to bureaucratic bottleneck. Due to the instability there are social upheavals, no basic government services reach the rural areas and increasing law and order problems. Furthermore, most state owned enterprises are technically insolvent and is largely attributed to political intervention and wantokism. The 'wantokism' is a cultural notion in a collectivist society, were the kin or clan takes precedent over oneself. In addition, the high turnover rate of managers in the public sector may contribute to the lack of continuity in public policy formulation and execution (Kavanamur, 2002). For instance the Treasury and Finance department has had six different secretaries in the last 5 years. Particularly for a national IS policy, no comprehensive policy guideline was put in place to take on this responsibility although several attempts have been made in the last few years. There were concerns by both organisations that the government at the national level was not providing the direction necessary to drive the IT industry in the country. One respondent in Organisation B stated, that they 'hardly get any interest with the government on IT'. Another respondent stated that, there was 'no push' or 'direction nor encouragement by the government'. As a result of the political and economic instability, law and order problems have 
escalated. Law and order is a major factor that has an impact on many organisations in the country. For example, telecommunication service lines were often disrupted when criminals dismantled solar panels from communication sites.

\section{Telecommunication infrastructure}

Telecommunication services is another factor that influences IS success in organisations in the country. Organisations depend on the communication infrastructure to effectively conduct their business. However, telecommunication infrastructure and services in the country was a major concern. Although PNG was encouraged to invest in IT infrastructure in order to contribute to economic growth and participate in the global trade, the government lacked the financial means to improve telecommunication infrastructure. A senior manager stated that, "the biggest problem with $P N G$ is communication and the communication network is a nightmare'. In addition telecommunication costs were high, as one respondent expressed, 'telecommunication has unrealistic prices... it is too expensive'. The vandalism of transmitter stations and land compensation claims by landowners may contribute to the disruption of telecommunication services. The people customarily own Land titles in PNG. Land compensation is one of the biggest hindrances to economic growth.

\section{National cultural issues}

Adler (1998) argues that the national culture has a greater impact on employees then does the organisational culture. National cultural issues and factors may have an underlying effect on IS adoption, use and success particularly for the LDCs. There were mixed feelings about the effect of culture on IS success in both organisations. IS was 'a fairly new thing' in many other organisations in PNG, therefore, employees were initially reluctant to use the system. A respondent at Organisation A commented that, generally 'most (employees) were happy and keen to use computer systems, however some users were shy with computers'. Although IS training and literacy programs may alleviate this fear and reluctance, there may be some cultural aspects such as uncertainty avoidance which may have its roots in the PNG cultural mind-set as a collectivist society.

Generally, employees tend to adapt the new technology, however one cultural concern was that PNGeans were usually less tolerant about the unknown and would refrain to avoid humiliation. One manager stated that PNGeans, 'hate to be shamed and humiliated, therefore we had to be very careful' during training sessions. It was argued that employees were willing to learn, however they tend to be passive and less tolerant to deviant ideas and maintain a rigid code of belief and ethics. PNG features close to a collectivist society, therefore, the cultural issue raised here may be exemplifying the belief that cultural factors influence on IS success in organisations in PNG.

\section{SUMMARY}

A number of factors and issues were identified and categorised into individual, organisational and external levels. The results are similar to that of factors identified by Jain (1997) and Ang, Davis \& Finlay (2001). IS are implemented in organisations which interact with the environment consisting of social, political, economical and cultural settings. Results in this study indicate that external settings influence IS success in the organisation. Therefore the government must play a leading role in setting the direction for IT development in the country if it is to confidently participate in the global environment. Strategic issues such as information policy guidelines, national infrastructure, and economic and political stability, must be addressed. In addition it should place an emphasis on human resources development and IT literacy programs because the availability of skilled IS professionals continues to be a major obstacle at the national level as reflected in the organisations. Unless this is achieved organisations will continue to rely on foreign expertise accumulating high costs. Cultural factors also impact the uptake of IS as these technologies impact social and technical change, therefore cultural implications must also be addressed.

The lack of IS knowledge, literacy and awareness was evident and need for IS training was emphasised by the organisations in this study. Organisations need to facilitate for IS literacy, training and awareness programs on a regular basis for all staff, particularly the top management. 
Management support and funding depends on how IS is perceived by top management. IS investment was profit oriented in both institutions. While funding was an obstacle to IS development in the Organisation A management felt that there is a lack of IS planning and direction at the national level. Similarly there was no coherence of the aligning of business and IS strategic planning. This may be attributed to proximity of the Chief Executive Officer (CEO) and the IS manager, however both organisations did not consider this factor to be important. System availability, accuracy and integrity of data and output were considered important in the organisations.

\section{CONCLUSION}

The results indicate that organisational and external factors have a strong influence on IS success in organisations in PNG. Political and economical instability, escalating law and order problems, provision of proper ICT infrastructure and the availability of skilled IS professionals have an impact on IS success in the organisations. The lack of IS literacy and training, and understanding the capabilities of IS by management results in the lack of proper IS planning and management. Unless there is IS literacy among managers, poor strategic decisions will continue to be made on isolated initiatives without preconceived strategies or plans. This also reflects the lack of direction and commitment at the national level, which can lead to uncoordinated efforts and waste of much needed resources from individual organisations in the country.

As a result of the poor economic environment and budget constraints, IS investments in PNG government organisations are minimal or in some instances nil. This has cultivated a dependency syndrome among organisations, where they depend on external funding from donor agencies or international organisations such as the United Nations Development Program (UNDP) for IS investment.

A top-down approach to IS development in PNG is necessary, where the national government advocates IS as a driver and strategic tool for change, and provide an overarching framework and direction for IS development in the country. Organisations will then function within this framework to coordinate their efforts in IS investment.

\section{REFERENCES}

Adler, N. J. (1986). International dimensions of organizational behaviour, Kent Publishing: Boston, MA.

Ang, C.-L., Davis, M. A., \& Finlay, P. N. (2001). An empirical model of IT usage in the Malaysian public sector. Journal of Strategic Information Systems, 10(2): 159-174

Anakwe, U. P., Anandarajan, M., \& Igbaria, M. (1999). Information technology usage dynamics in Nigeria: An empirical study. Journal of Global Information Management, 7(2): 13-21.

Bailey, G. E., \& Pearson, S. W. (1983). Development of tool for measuring and analysing computer user satisfaction. Journal of Management Science, 29(5):530-545.

Bajwa, D., Rai, A., \& Brennan, I. (1998). Key antecedents of executive information systems success: A path analytic approach. Decision Support Systems, 22: 31-43.

Delone, W. H., \& McLean, E. R. (1992). Information systems success: The quest for dependent variable. Information Systems Research, 3(1): 60-95.

Ein-Dor, P., Segev, E., \& Orgad, M. (1993). The effect of national culture on IS: Implication for international information systems. Journal of Global Information Management, 1(1): 33-44.

Grover, V., Jeong, S. R., \& Segars, A. H. (1996). Information systems effectiveness: The construct space and patterns of application. Information \& Management, 31(4): 177-191.

Hall, E. T. (1977). Beyond culture. Anchor Press: NY.

Harris, H., \& Davison, R. (1999). Anxiety and involvement: Cultural dimensions toward computers in developing societies. Journal of Global Information Management, 7(1): 26-38.

Hofstede, G. (1983). Culture and management development. UNDP/ILO: Geneva.

Hofstede, G. (1997). Cultures and organizations: software of the mind. McGraw-Hill: NY.

Jain, R. (1997). Key constructs in successful IS implementation: South -East Asian experience. Omega International Journal of Management Science, 25(1): 267-284. 
Kavanamur, D. (2002), The interplay between politics and business in Papua New Guinea, (State, Society and Governance in Melanesia Project Working Paper 01/6). Retrieved May 24, 2003, from http://rspas.anu.edu.au/melanesia/PDF/workingpaperkavanamur01 6.pdf

Larsen, M. A., \& Myers, M. D. (1999). When success turns into failure: a package-driven business process re-engineering project in the financial services industry, Journal of Strategic Information Systems, 8(4): 395-417.

Lyytinen, K. (1987). Different perspectives on IS: problems and solutions. ACM Computing Surveys, 19 (1): 1-46.

Markus, M. L., \& Robey, D. (1988). Information technology and organizational change: casual structure in theory and research. Management Science, 14(5): 583-598.

Miles, B. M., \& Huberman, A. M. (1994). Qualitative analysis (2nd ed.). Sage Publications: Thousand Oaks, CA.

Miller, J., \& Doyle, B. A. (1987). Measuring the effectiveness of computer-based information systems in the financial services sector. MIS Quarterly, 11(1): 106-123.

Myers, B. L., Kappelman, L. A., \& Prybutok, V. R. (1998). A comprehensive model for assessing the quality and productivity of information systems functions: toward a theory of information systems assessments. In E. Garrity \& G. L. Sanders (Eds.), Information Systems Success Measurements (pp. 94-121) Idea Group: Hershey, PA.

Myers, B. L., \& Tan, F. (2002). Beyond Models of National Culture in Information Systems Research. Journal of Global Information Management, pp. 24-32.

Neuman, W. L. (2000). Social research methods, qualitative and quantitative approaches $\left(4^{\text {th }}\right.$ ed.). Allyn and Bacon: Boston.

Odedra-Straub, M. (1993). Critical factors affecting success of CBIS: Cases from Africa. Journal of Global Information Management, 1(3): 16-32.

Yin, R. K. (1994). Case study research: Design and method ( $2^{\text {nd }}$ ed.). SAGE Publications: Thousand Oaks, CA. 